\title{
Análise de eficiência para as variáveis de fronteira
}

\author{
Michelle Márcia Viana Martins*
}

\begin{abstract}
Resumo
Medidas que visam acelerar e coordenar os processos comerciais são vistas, progressivamente, como uma forma de desenvolver e elevar as trocas entre as nações. Nesse sentido, o debate acerca das medidas de facilitações de comércio ganha espaço nas rodadas multilaterais, ao aumentar a influência dos procedimentos de fronteira para elevar as trocas comerciais. Este trabalho tem como objetivo fazer uma análise de eficiência, pelo método DEA, para identificar quais países, em 2014, foram eficientes em elevar seus fluxos de comércio ao utilizar as medidas propostas pelo Acordo de Facilitação de Comércio. Alemanha e Estados Unidos são, de maneira geral, os eficientes em escala em exportar e importar. Porém, Cingapura destacou-se como principal benchmark, sua administração alfandegária é uma das melhores do mundo e serve de exemplo para os países ineficientes. Entre os países em desenvolvimento, China é destaque nos seus processos comerciais.
\end{abstract}

Palavras-chave: Acordo de Facilitação de Comércio. Análise de eficiência. Fluxos comerciais.

Economista e doutoranda em Economia Aplicada (ESALQ/USP). E-mail: michellemartins@usp.br

http://dx.doi.org/10.5335/rtee.v25i53.10008

Submissão: 29/09/2018. Aceite: 18/09/2020. 


\section{Introdução}

A crescente competição mundial e o apogeu da globalização estimularam a redução dos custos e a elevação das trocas comerciais mundiais, acentuadas pela queda de tarifas e por outros esforços para liberalizar o comércio. O novo padrão de concorrência nos mercados externos impulsionou a modernização administrativa e operacional das aduanas. Consequentemente, políticas para a promoção da desburocratização e redução dos tempos consumidos nos despachos alfandegários de mercadorias, são recomendadas como forma de aprimorar o comércio.

Uma maior importância relativa é, então, atribuída aos procedimentos de fronteira como determinante dos custos de comercialização associadas às transações internacionais. Esses procedimentos estão relacionados às medidas que visam facilitar o comércio nos processos alfandegários, o que pode reduzir os custos associados ao comércio bilateral que impactam as relações de comerciais entre dois países (WILSON; MANN; OTSUKI, 2005).

Nesse contexto, em 2013, na Conferência Ministerial de Bali, foi proposto o Acordo de Facilitação de Comércio (AFC), com o objetivo de minimizar os custos excessivos envolvidos na comercialização de bens transfronteiriços. Na ocasião, ficou estabelecido que este entraria em vigor quando dois terços dos membros da Organização Mundial do Comércio (OMC) assinassem um termo de comprometimento à sua adesão. Em fevereiro de 2017, foi atingido o número de assinaturas e o acordo foi ratificado.

O AFC contém disposições para agilizar o movimento, a liberação e o despacho de mercadorias, incluindo aquelas em trânsito. A sua implementação cria um impulso significativo para o comércio e para o sistema comercial multilateral como um todo, incluindo benefícios adicionais em variáveis econômicas e sociais em comparação aos acordos alcançados unilateralmente. Ao reduzir os custos de transações, a facilitação de comércio contempla tanto os países importadores, que são favorecidos por preços mais baixos, quanto os exportadores, que recebem um preço mais elevado pelo aumento de volume do bem transacionado.

A eficiência aduaneira é um dos principais elementos de fronteira a ser abordado pelo AFC. As atribuições concedidas às alfandegas representam um impacto significativo na redução de custos associados à gestão do desempenho comercial. Uma má administração aduaneira pode afetar as melhorias que foram feitas em outras áreas relacionadas ao comércio internacional, por exemplo, uma melhoria na infraestrutura dos portos. Em tais condições, as administrações aduaneiras são 
operadores reguladores relevantes no movimento de mercadorias e devem atuar facilitando e acelerando o comércio internacional.

Os trabalhos que analisam os efeitos da facilitação do comércio sobre o fluxo comercial o fazem sob uma perspectiva econométrica. Engman (2005) analisa o impacto da facilitação do comércio sobre os fluxos comerciais e o investimento direto estrangeiro (IDE). Os resultados indicam que quanto menor o número de procedimentos aduaneiros, maiores os impactos positivos sobre os fluxos comerciais. Além disso, quanto mais facilitada a movimentação transfronteiriça de bens, maior a capacidade do país em atrair IDE e melhor integrar-se nas cadeias internacionais de produção.

Djankov, Freund e Pham (2006) utilizam variáveis de fronteira para mensurar o efeito da facilitação do comércio sobre o volume comercializado, para 126 países com diferentes níveis de renda. Os autores indicam que os custos comerciais são diretamente afetados pelo tempo em que as mercadorias são retidas nos postos alfandegários, impactando significativamente os fluxos comerciais. De acordo com os autores, a cada um dia adicional de atraso na entrega, o comércio é reduzido em pelo menos 1\%. Seguindo a mesma linha, Hummels e Schaur (2012) examinam o tempo como obstáculo comercial norte-americano, através de uma avaliação econométrica. É verificado que a cada dia adicional necessário para o transporte, há redução de cerca de $1 \%$ na possibilidade de um país comercializar com os Estados Unidos.

Na sequência, Sadikov (2007) avalia os impactos das barreiras administrativas associadas ao comércio internacional, definidas como o número de documentos exigidos para exportar e o número de procedimentos necessários para registro de negócios, para 140 economias. Para cada documento adicional exigido para exportar, estima-se uma redução em 4,2\% no volume de exportações. Esse resultado encontra respaldo em Hummels e Schaur (2012) e em Djankov, Freund e Pham (2006), ao elucidarem que o excesso de documentos e procedimentos torna o processo comercial moroso, elevando o tempo de retenção das mercadorias.

Li e Wilson (2009) e Souza e Burnquist (2011) utilizam a abordagem do modelo gravitacional para verificar os impactos da facilitação de comércio sobre as transações comerciais. Os autores ressaltam que os procedimentos alfandegários e administrativos, mais especificamente, o número de documentos necessários para importar e exportar, o número de assinaturas e aprovações necessárias para satisfazer as formalidades e o número de dias para comercializar, impactam negativamente no comércio bilateral dos países. Como resultado, fica claro que o grau de facilitação comercial das nações que comercializam no mercado internacional é um importante determinante do padrão de comércio. 
Diante da implementação do AFC, estima-se uma redução de $14 \%$ dos custos totais em países de baixa renda e de $13 \%$ em países de renda média alta, proporcionando um aumento de 4,7\% do PIB global (WTO, 2015a). Os ganhos marginais das facilitações de comércio são superiores em países menos desenvolvidos, dado que os custos de transação comercial são mais elevados pela inerente escassez de recursos, infraestrutura rígida e presença de gargalos que dificultam o comércio. No entanto, desenvolver os procedimentos de fronteiras, seja pela melhoria do sistema aduaneiro, pelo aperfeiçoamento do sistema logístico ou por melhores condições de infraestrutura, demanda múltiplos recursos que os governos de países de baixa renda não têm condições de financiar (WTO, 2015a, 2015b).

Com o objetivo de fomentar foros de discussão sobre questões de governança nacional e global que afetam o comércio a nível internacional, apontando para políticas que possam reduzir os custos totais de comércio dos países, este estudo visa preencher uma lacuna concernente ao entendimento da dinâmica da eficiência da facilitação de comércio sobre o volume comercializado. Logo, pretende-se identificar quais países - signatários do AFC - foram eficientes em elevar o fluxo comercial, no ano de 2014, ao adequarem-se às medidas propostas pelo acordo, como a redução as formalidades burocráticas e o tempo de movimentação de mercadorias pelas fronteiras. Para atender o objetivo, será utilizado o método da Análise Envoltória de Dados (DEA - Data Envelopment Analysis).

Além desta introdução, o trabalho está estruturado em mais três seções. $\mathrm{Na}$ segunda, são apresentadas as especificações metodológicas. Posteriormente, há uma discussão sobre a análise de eficiência e o apontamento dos benchmarkings para os fluxos de exportação e importação. Por fim, são expressas as considerações finais.

\section{Metodologia}

\section{Análise envoltória de dados}

Para medir o grau de eficiência das economias mundiais, utilizou-se uma técnica não paramétrica baseada em programação matemática, a metodologia DEA, ou análise envoltória de dados. Através do método é possível analisar o desempenho operacional de unidades independentes, podendo ser países, empresas, departamentos, divisões ou afins. A medida de eficiência é dada de forma comparativa, 
ou seja, é relativa e dependente da amostra de dados. Na literatura relacionada aos modelos DEA, cada unidade produtiva (no caso deste estudo, cada país) é tratada como uma unidade tomadora de decisão, denominada DMU (Decision Making Unit), sendo representada por um conjunto de inputs e outputs.

A análise de eficiência pode ser separada em eficiência técnica e alocativa. A primeira refere-se à capacidade de uma unidade produtiva maximizar seu produto, estando restrita a um conjunto de insumos. Já a eficiência alocativa reflete a habilidade de uma unidade produtiva em utilizar os insumos em proporções ótimas, dados seus preços relativos. A combinação desses dois tipos de eficiência resulta em uma medida de eficiência econômica total.

Além disso, pode-se optar por um dos dois tipos de orientações ao utilizar o modelo DEA, quais sejam: i) orientação produto, que visa a maximização dos outputs, mantendo-se fixos os inputs; ii) orientação insumo, fundamentada na minimização dos inputs, mantendo-se fixo o nível de produção - outputs. Este estudo é embasado na orientação insumo, pois, para uma tecnologia dada, a fronteira de produção caracteriza o conjunto mínimo de procedimentos de fronteira (inputs) necessários para produzir quantidades fixas de exportação e importação (outputs).

Algumas pressuposições fundamentais na técnica DEA, citadas por Lins e Meza (2000), desconsideram a necessidade de converter insumos e produtos em unidades monetárias, diferentemente de modelos baseados em análises puramente econômicas. Além disso, conceituam como eficientes os setores que operam com DMU igual a 1, sendo consideradas benchmarks para os setores ineficientes.

A modelagem DEA comporta retornos constantes e variáveis à escala de produção. O modelo de retornos constantes (CCR), proposto por Charnes, Cooper e Rhodes (1978), avalia a eficiência total: identifica as unidades eficientes e ineficientes e quão distantes estas estão da fronteira da eficiência. O modelo de retornos variáveis de escala (BBC), proposto por Banker, Charnes e Cooper (1984), além de apontar quais unidades são eficientes ou não, é usual para a verificação dos benchmarkings. Dessa forma, foi adotado este último modelo para a presente proposta, sendo representado pelo seguinte problema de programação matemática: 


$$
\begin{gathered}
\operatorname{Min}_{\emptyset, \lambda} \phi, \\
\text { sujeito } a: \\
-\phi y_{i}+Y \lambda \geq 0 \\
x_{i}-X \lambda \geq 0 \\
N^{\prime}{ }_{1} \lambda=1 \\
\lambda \geq 0
\end{gathered}
$$

Em que $N_{1}^{\prime} \lambda=1$ representa uma restrição de convexidade, sendo $N_{1}$ um vetor de algarismos unitários na ordem ( $m \times 1)$. A medida $\phi$ varia no intervalo de $1 \leq \phi \leq \infty ; \emptyset-1$ corresponde ao aumento proporcional no produto considerado, dado constante o conjunto de insumos, ou seja, é a variação do produto necessária para que a DMU seja considerada eficiente. Já $1 / \varnothing$ representa a eficiência técnica que varia no intervalo [0,1]. Para a $i$-ésima observação: $x_{i}$ é um vetor $(k \times 1)$ de quantidades de insumo; $y_{i}$ é um vetor $(n \times 1)$ de quantidades de produto; o parâmetro $\lambda$ é um vetor ( $m$ x 1 ) de pesos, cujos valores são calculados de forma a obter uma solução ótima.

\section{Procedimentos metodológicos, variáveis utilizadas e fonte de dados}

Dada a disponibilidade de dados, foram considerados 129 países na amostra, divididos em quatro grupos, de acordo com seu nível de desenvolvimento: renda alta, renda média alta, renda média baixa e renda baixa. Essa classificação é coerente com a proposta pelas Nações Unidas (2014). Segue, no Quadro 1, a classificação das economias e suas respectivas DMUs. 
Quadro 1 - Classificação dos países de acordo com o nível de desenvolvimento

\begin{tabular}{|c|c|c|c|c|c|c|c|c|c|c|c|c|c|}
\hline \multicolumn{4}{|c|}{ Renda Alta } & \multicolumn{4}{|c|}{ Renda Média Alta } & \multicolumn{4}{|c|}{ Renda Média Baixa } & \multicolumn{2}{|c|}{ Renda Baixa } \\
\hline$\sum_{0}^{2}$ & Economia & $\underset{D}{2}$ & Economia & $\sum_{\Delta}^{2}$ & Economia & $\sum_{0}^{2}$ & Economia & $\sum_{0}^{2}$ & Economia & $\sum_{0}^{2}$ & Economia & $\stackrel{2}{D}$ & Economia \\
\hline 1 & Alemanha & 24 & Hong Kong & 1 & África do Sul & 24 & México & 1 & Afeganistão & 24 & $\begin{array}{l}\text { Sri } \\
\text { Lanka }\end{array}$ & 1 & Benin \\
\hline 2 & $\begin{array}{l}\text { Arábia } \\
\text { Saudita }\end{array}$ & 25 & Irlanda & 2 & Angola & 25 & Montenegro & 2 & Armênia & 25 & Ucrânia & 2 & $\begin{array}{l}\text { Burkina } \\
\text { Faso }\end{array}$ \\
\hline 3 & Austrália & 26 & Islândia & 3 & Argélia & 26 & Namíbia & 3 & Bolívia & 26 & Vietnã & 3 & Burundi \\
\hline 4 & Áustria & 27 & Israel & 4 & Argentina & 27 & Panamá & 4 & Camarões & 27 & Zâmbia & 4 & Congo \\
\hline 5 & Barém & 28 & Itália & 5 & Azerbaijão & 28 & Peru & 5 & Camboja & & & 5 & Eritreia \\
\hline 6 & Bélgica & 29 & Japão & 6 & $\begin{array}{l}\text { Bósnia e } \\
\text { Herzegovina }\end{array}$ & 29 & $\begin{array}{l}\text { República } \\
\text { Dominicana }\end{array}$ & 6 & $\begin{array}{l}\text { Costa do } \\
\text { Marfim }\end{array}$ & & & 6 & Etiópia \\
\hline 7 & Canadá & 30 & Kuwait & 7 & Botsuana & 30 & Romênia & 7 & Egito & & & 7 & Gâmbia \\
\hline 8 & Catar & 31 & Letônia & 8 & Brasil & 31 & Sérvia & 8 & El Salvador & & & 8 & Guiné \\
\hline 9 & Chile & 32 & Lituânia & $|9|$ & Bulgária & 32 & Tailândia & 9 & Filipinas & & & 9 & Laos \\
\hline 10 & Chipre & 33 & Luxemburgo & $|10|$ & Cazaquistão & 33 & Tunísia & 10 & Geórgia & & & 10 & Madagascar \\
\hline 11 & Cingapura & 34 & Malta & 11 & China & 34 & Turquia & 11 & Guatemala & & & 11 & Maláui \\
\hline 12 & $\begin{array}{l}\text { Coreia, } \\
\text { República da }\end{array}$ & 35 & Noruega & 12 & Colômbia & & & 12 & Guiana, RC & & & 12 & Mali \\
\hline 13 & Croácia & 36 & $\begin{array}{l}\text { Nova } \\
\text { Zelândia }\end{array}$ & 13 & $\begin{array}{l}\text { Congo, } \\
\text { República } \\
\text { do }\end{array}$ & & & 13 & Honduras & & & 13 & Moçambique \\
\hline 14 & Dinamarca & 37 & Omã & 14 & Costa Rica & & & 14 & lémen & & & 14 & Nepal \\
\hline 15 & $\begin{array}{l}\text { Emirados } \\
\text { Árabes }\end{array}$ & 38 & $\begin{array}{l}\text { Países } \\
\text { Baixos }\end{array}$ & 15 & Equador & & & 15 & Índia & & & 15 & Níger \\
\hline 16 & Eslováquia & 39 & Polônia & 16 & Gabão & & & 16 & Indonésia & & & 16 & Quênia \\
\hline 17 & Eslovênia & 40 & Portugal & 17 & Hungria & & & 17 & Mauritânia & & & 17 & Quirguistão \\
\hline 18 & Espanha & 41 & Reino Unido & 18 & Iraque & & & 18 & Moldova & & & 18 & $\begin{array}{l}\text { República } \\
\text { Centro- } \\
\text { Africana }\end{array}$ \\
\hline 19 & $\begin{array}{l}\text { Estados } \\
\text { Unidos }\end{array}$ & 42 & $\begin{array}{l}\text { República } \\
\text { Checa }\end{array}$ & 19 & Jamaica & & & 19 & Nicarágua & & & 19 & Ruanda \\
\hline 20 & Estônia & 43 & Rússia & 20 & Jordânia & & & 20 & Nigéria & & & 20 & Tanzânia \\
\hline 21 & Finlândia & 44 & Suécia & 21 & Líbano & & & 21 & Paquistão & & & 21 & Togo \\
\hline 22 & França & 45 & Suíça & 22 & Macedônia & & & 22 & Paraguai & & & 22 & Zimbábue \\
\hline 23 & Grécia & 46 & Uruguai & 23 & Malásia & & & 23 & Senegal & & & & \\
\hline
\end{tabular}

Fonte: World Economic Situation and Prospects (NAÇÕES UNIDAS, 2014).

Para que as transações comerciais sejam mais rápidas e harmoniosas, o AFC exige que os membros da OMC adotem medidas que acelerem o trâmite de liberação e entrega das mercadorias. Com efeito, as dificuldades experimentadas por países desenvolvidos e menos desenvolvidos são diferentes, o que justifica a separação dos países em grupos de desenvolvimento. Deve-se atentar ao fato de que o comércio é bilateral. Assim, enquanto os países de renda alta enfrentam desafios associados à lentidão e à burocracia exigidas nas operações comerciais de produtos 
provenientes de economias de baixa renda, esses últimos enfrentam obstáculos que vão além dos procedimentos de fronteira, por exemplo, dificuldades associadas aos processos logísticos, tecnológicos e até mesmo ao atendimento dos padrões de qualidade internacional.

A análise de eficiência será calculada mediante a minimização dos insumos, que são as variáveis que representam as medidas de fronteira propostas pelo AFC, em duas vertentes: a primeira é sobre a ótica da exportação e a segunda é sobre o ponto de vista das importações. Neste caso, há dois blocos de insumos e produtos, descritos na Tabela 1.

Tabela 1 - Variáveis utilizadas na análise de eficiência

\begin{tabular}{l|l|l}
\hline Fluxo comercial & \multicolumn{1}{|c|}{ Produto } & \multicolumn{1}{c}{ Insumos } \\
\hline \multirow{2}{*}{ Exportação } & \multirow{2}{*}{$\begin{array}{l}\text { Volume exportado do país i, no } \\
\text { ano de 2014 (em 1.000.000 US\$) }\end{array}$} & Documentos para exportar (número) \\
\cline { 3 - 3 } & & Tempo para exportar (dias) \\
\cline { 3 - 3 } Importação & \multirow{2}{*}{$\begin{array}{l}\text { Volume importado pelo país i, no } \\
\text { ano de 2014 (em 1.000.000 US\$) }\end{array}$} & Documentos para importar (número) \\
\cline { 3 - 3 } & & Tempo para importar (dias) \\
\cline { 3 - 3 } & & Custo para importar (US\$ por contêiner) \\
\hline
\end{tabular}

Fonte: elaboração da autora.

Os dados referentes aos fluxos comerciais foram coletados na base estatística United Nations Conference on Trade and Development (UNCOMTRADE), disponível no World Integrated Trade Solutions (WITS). O número de documentos, o tempo e o custo para exportar/importar são encontrados no portal Doing Business.

O tempo para exportar/importar considera o número de dias para o produto chegar ao local de destino. O número de documentos pondera as regulamentações alfandegárias e outras normatizações relacionadas às inspeções que são obrigatórias para que a mercadoria atravesse a fronteira. Os custos de comércio medem as taxas associadas ao fim do procedimento de importar e exportar, cobradas em um contêiner de 20 pés, em dólares americanos. Nesses custos estão inclusos os gastos documentais, as taxas administrativas para despacho aduaneiro e inspeções, as taxas relacionadas ao porto e os custos de transporte terrestre. Não estão inclusos os custos tarifários e os custos do transporte marítimo. 


\section{Resultados}

\section{Eficiência nas exportações}

As economias com maior fluxo comercial em 2014 foram China, Alemanha, Estados Unidos, Coreia do Sul e Países Baixos. Entre esses países de renda alta, a Alemanha destacou-se com o maior volume exportado (9,35\%), sendo $50 \%$ da pauta exportadora alemã composta por maquinários, produtos elétricos e transporte. Aproximadamente 66\% das mercadorias tiveram destino na Europa, sendo a França o seu principal parceiro comercial. Para os países de renda média alta, a China figura como a maior exportadora mundial (17,55\%). Do total, $27,40 \%$ correspondem aos produtos eletrônicos, $22,22 \%$ aos maquinários e $15,21 \%$ aos produtos têxteis. Além disso, 44,60\% das mercadorias tiveram como destino a Ásia, 24,68\% a América do Norte e 21,56\% a Europa. Nas classificações posteriores, destacam-se Índia $(2,47 \%$ do total mundial) e Eritreia $(0,20 \%)$ como os países que mais exportaram entre aqueles de renda média baixa e renda baixa, respectivamente.

A desburocratização e a redução do tempo necessário para comercializar traduzem-se em um comércio mais simplificado, com consequente redução de custos para os agentes envolvidos. A Tabela 2 apresenta o panorama das variáveis de facilitação de comércio. À medida que reduz o nível de desenvolvimento dos países, maiores são os valores atribuídos às variáveis, indicando processos alfandegários onerosos e burocráticos. Da mesma forma, países mais desenvolvidos tendem a apresentar processos mais ágeis. O menor número de documentos para exportar, por exemplo, é referente às economias de alta renda. As economias francesa e irlandesa exigem apenas dois documentos para seus trâmites comerciais. Em contrapartida, Congo (renda média alta) e Camarões (renda média baixa) são os mais burocráticos no quesito exportação (11) ${ }^{1}$, ambos fazem parte da Organização para a Cooperação Econômica da Ásia Central, que apresenta como um dos principais objetivos facilitar a liberalização comercial dos membros. Logo, é esperado que futuramente as variáveis em análise apresentem melhorias para esses países. 
Tabela 2 - Estatística das variáveis de fronteira por classificação de países nas exportações

\begin{tabular}{l|l|r|r|r}
\hline \multicolumn{5}{c}{ Exportação } \\
\hline \multirow{4}{*}{ Renda Alta } & Média & № de documentos & \multicolumn{1}{c}{ Tempo } & \multicolumn{1}{c}{ Custo } \\
& Máximo & 4.2 & 11.02 & 1030.28 \\
& Mínimo & 9.00 & 22.00 & 2337.50 \\
& Desvio Padrão & 2.00 & 6.00 & 460.00 \\
& Média & 1.38 & 4.11 & 355.22 \\
\hline \multirow{5}{*}{ Renda Média Alta } & Máximo & 6.24 & 21.41 & 1663.61 \\
& Mínimo & 11.00 & 81.00 & 4885.00 \\
& Desvio Padrão & 3.00 & 8.00 & 450.00 \\
& Média & 2.05 & 17.21 & 1030.41 \\
\hline \multirow{5}{*}{ Renda Média Baixa } & Máximo & 7.04 & 23.44 & 1453.16 \\
& Mínimo & 11.00 & 81.00 & 4645.00 \\
& Desvio Padrão & 4.00 & 9.00 & 585.00 \\
& Média & 1.76 & 14.19 & 992.4 \\
\hline & Máximo & 7.95 & 35.14 & 2383.05 \\
& Mínimo & 11.00 & 63.00 & 5490.00 \\
& Desvio Padrão & 5.00 & 18.00 & 915.00 \\
& & 1.70 & 13.26 & 1279.32 \\
\hline
\end{tabular}

Fonte: elaboração da autora.

O tempo de desembaraço alfandegário é associado a um processo burocrático, uma vez que a redução do número de dias para que um bem chegue ao destino pode ser entendida como uma medida de simplificação dos procedimentos de fronteira. De forma análoga, quanto menor o nível de desenvolvimento dos países, maior o tempo necessário para que o comprador receba sua mercadoria. No tocante aos custos comerciais, Cazaquistão (US\$4885,00) é o país que apresenta o maior custo para exportar um contêiner de 20 pés. Já Cingapura (US\$460) é o menos custoso. Na média, países de renda baixa são mais dispendiosos para comercializar, o que pode ser justificado pela infraestrutura e pelas condições comerciais precárias.

Em relação à análise de eficiência, inicialmente, obteve-se as DMUs eficientes para os países de renda alta (Tabela 3). Atenção é dada a Alemanha e Estados Unidos, pois estes se apresentaram como eficientes em escala, ou seja, utilizaram as medidas de facilitação de comércio com maior eficiência para elevar seus fluxos comerciais de exportação. As duas economias destacam-se como potências que competem mundialmente com produtos de alta tecnologia, demandando uma força de trabalho altamente qualificada, o que pode contribuir para gerar transbordamentos em processos alfandegários mais automatizados. Esse argumento é ressaltado 
pelo relatório do World Economic Forum (WEF) (2019), ao afirmar que o país norte-americano se destaca pelo uso da tecnologia de informação no estabelecimento das transações comerciais. Contudo, em termos de serviços logísticos, a Alemanha é considerada referência mundial, sendo um dos mais pontuais e ágeis do mundo, o que pode corroborar para sua DMU máxima.

No que concerne à eficiência técnica, Cingapura, Dinamarca, Estônia, França, Hong Kong e Irlanda são tecnicamente eficientes. Esse resultado indica que os requisitos alfandegários no processo de exportação foram minimizados de forma a prover maior facilidade em exportar.

Tabela 3 - Análise de eficiência nas exportações para países de renda alta

\begin{tabular}{|c|c|c|c|c|c|c|c|c|c|c|c|}
\hline \multicolumn{12}{|c|}{ Exportação } \\
\hline DMU & Economia & $\mathrm{ET}^{*}$ & $E E^{* *}$ & DMU & Economia & ET & EE & DMU & Economia & ET & $\mathrm{EE}$ \\
\hline 1 & Alemanha & 1.000 & 1.000 & 17 & Eslovênia & 0.617 & 0.040 & 33 & Luxemburgo & 0.750 & 0.011 \\
\hline 2 & $\begin{array}{l}\text { Arábia } \\
\text { Saudita }\end{array}$ & 0.487 & 0.393 & 18 & Espanha & 0.667 & 0.277 & 34 & Malta & 0.588 & 0.006 \\
\hline 3 & Austrália & 0.667 & 0.216 & 19 & \begin{tabular}{|l} 
Estados \\
Unidos
\end{tabular} & 1.000 & 1.000 & 35 & Noruega & 0.750 & 0.118 \\
\hline 4 & Áustria & 0.803 & 0.000 & 20 & Estônia & 1.000 & 0.016 & 36 & Nova Zelândia & 0.698 & 0.040 \\
\hline 5 & Barém & 0.568 & 0.028 & 21 & Finlândia & 0.750 & 0.097 & 37 & Omã & 0.617 & 0.067 \\
\hline 6 & Bélgica & 0.706 & 0.396 & 22 & França & 1.000 & 0.608 & 38 & Países Baixos & 0.857 & 0.280 \\
\hline 7 & Canadá & 0.857 & 0.371 & 23 & Grécia & 0.667 & 0.034 & 39 & Polônia & 0.563 & 0.219 \\
\hline 8 & Catar & 0.578 & 0.000 & 24 & Hong Kong & 1.000 & 0.016 & 40 & Portugal & 0.715 & 0.069 \\
\hline 9 & Chile & 0.571 & 0.083 & 25 & Irlanda & 1.000 & 0.127 & 41 & Reino Unido & 0.750 & 0.454 \\
\hline 10 & Chipre & 0.857 & 0.001 & 26 & Islândia & 0.667 & 0.004 & 42 & Rep. Checa & 0.638 & 0.163 \\
\hline 11 & Cingapura & 1.000 & 0.538 & 27 & Israel & 0.749 & 0.000 & 43 & Rússia & 0.307 & 0.458 \\
\hline 12 & Coreia, Rep. & 0.924 & 0.001 & 28 & Itália & 0.810 & 0.454 & 44 & Suécia & 0.906 & 0.158 \\
\hline 13 & Croácia & 0.463 & 0.000 & 29 & Japão & 0.946 & 0.604 & 45 & Suíça & 0.857 & 0.259 \\
\hline 14 & Dinamarca & 1.000 & 0.000 & 30 & Kuwait & 0.428 & 0.000 & 46 & Uruguai & 0.481 & 0.010 \\
\hline 15 & $\begin{array}{l}\text { Emirados } \\
\text { Árabes }\end{array}$ & 0.929 & 0.254 & 31 & Letônia & 0.767 & 0.000 & & & & \\
\hline 16 & Eslováquia & 0.512 & 0.081 & 32 & Lituânia & 0.721 & 0.036 & & & & \\
\hline \multicolumn{10}{|c|}{ Média Global } & 0.743 & 0.195 \\
\hline
\end{tabular}

*ET: Eficiência técnica; **EE: Eficiência de escala.

Fonte: elaboração da autora, resultado da análise.

Em relação aos benchmarks, Cingapura foi referência para 39 países ineficientes nas exportações, seguida de Irlanda (26), Estados Unidos (17) e França (3). Visto que o AFC propõe que todos os países membros da OMC direcionem seus esforços para melhorarem as variáveis de fronteira, esse resultado indica que as políticas alfandegárias adotadas em Cingapura têm sido satisfatórias para atingir os objetivos propostos pelo acordo. De fato, o país asiático é a economia líder em 
administração de fronteiras e serviços de transporte, sendo a melhor avaliada em relação à qualidade e à abrangência dos postos alfandegários (WEF, 2019). Além disso, foi o primeiro país a implementar o sistema de janela única ${ }^{2}$ no mundo, servindo de exemplo global para as melhores práticas de regulamentação de serviços facilitadores de comércio.

Na Tabela 4 são indicadas as análises de eficiência para países de renda média alta, em que China, Jamaica, Macedônia e República Dominicana operam na fronteira de escala ótima, enquanto África do Sul, Costa Rica, Jordânia, Macedônia, México e Montenegro foram os países tecnicamente eficientes em exportar.

Tabela 4 - Análise de eficiência nas exportações para países de renda média alta

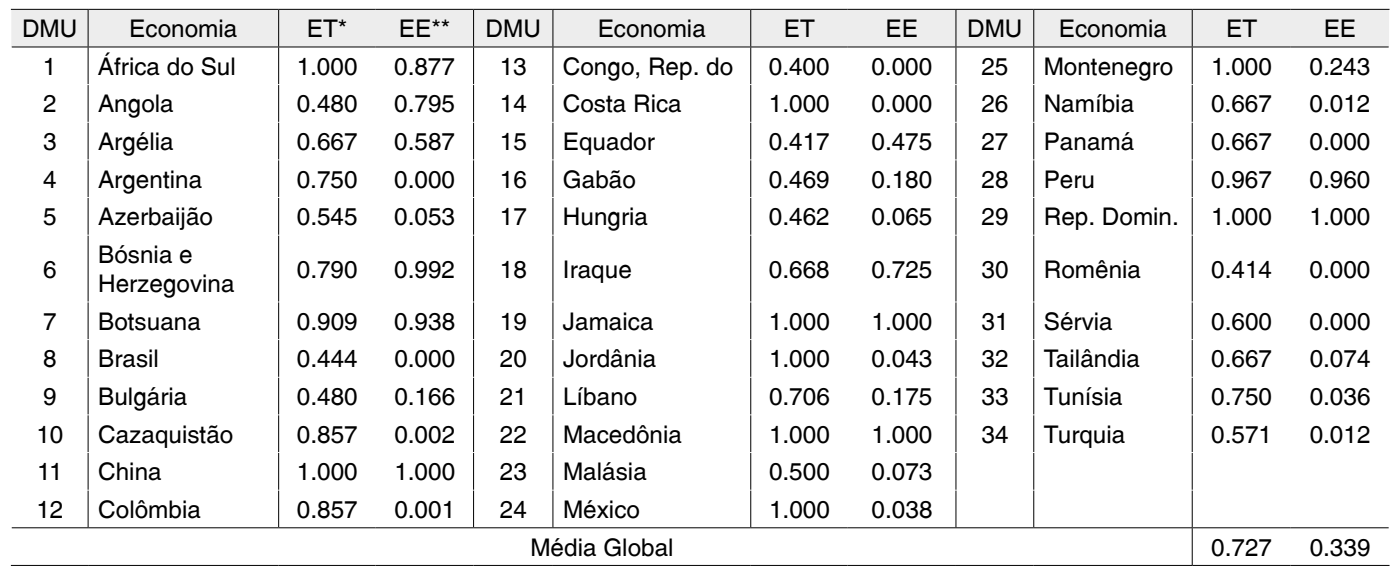

*ET: Eficiência técnica; **EE: Eficiência de escala.

Fonte: elaboração da autora, resultado da análise.

As economias que obtiveram DMUs iguais a 1 para eficiência técnica apresentaram o número de documentos e o tempo para exportar inferiores à média do grupo. Em relação aos custos de exportação, com exceção da África do Sul, os valores apresentaram-se, também, abaixo da média amostral.

Em relação aos benchmarks, a China foi referência para 27 economias ineficientes, seguida de Montenegro (16), Macedônia (5) e República Dominicana (2). Tanto China quanto Montenegro são países que apresentam os melhores indicadores de transparência na administração de fronteiras, em relação aos demais membros do mesmo grupo, o que pode justificar o resultado dos benchmarks (WEF, 2019). 
Na Tabela 5 são expostos os escores de eficiência para os países com menor nível de desenvolvimento. Entre as nações de renda média baixa, Índia e Indonésia obtiveram eficiência total, operando na escala ótima nas exportações. Em relação à eficiência técnica, destacam-se Índia, sendo benchmark em exportação para 22 países ineficientes, Geórgia (15), Egito (10), Filipinas (4) e Indonésia (1). Para países de renda baixa, o único país que obteve eficiência total foi Eritreia, e os eficientes técnicos foram Gâmbia (7), Guiné (1), Madagascar (12), Moçambique (4), Tanzânia (2) e Togo (0).

Tabela 5 - Análise de eficiência nas exportações para países de renda média baixa e renda baixa

\begin{tabular}{|c|c|c|c|c|c|c|c|c|c|c|c|}
\hline \multicolumn{12}{|c|}{ Exportação - Renda Média Baixa } \\
\hline DMU & Economia & $\mathrm{ET}^{*}$ & $E E^{\star \star}$ & DMU & Economia & ET & EE & DMU & Economia & ET & EE \\
\hline 1 & Afeganistão & 0.400 & 0.003 & 10 & Geórgia & 1.000 & 0.000 & 19 & Nicarágua & 0.800 & 0.027 \\
\hline 2 & Armênia & 0.800 & 0.008 & 11 & Guatemala & 0.674 & 0.054 & 20 & Nigéria & 0.533 & 0.493 \\
\hline 3 & Bolívia & 0.630 & 0.064 & 12 & Guiana & 0.829 & 0.007 & 21 & Paquistão & 0.767 & 0.143 \\
\hline 4 & Camarões & 0.555 & 0.027 & 13 & Honduras & 0.873 & 0.025 & 22 & Paraguai & 0.571 & 0.053 \\
\hline 5 & Camboja & 0.737 & 0.040 & 14 & lémen & 0.667 & 0.011 & 23 & Senegal & 0.876 & 0.015 \\
\hline 6 & Costa do Marfim & 0.519 & 0.053 & 15 & Índia & 1.000 & 1.000 & 24 & Sri Lanka & 0.984 & 0.064 \\
\hline 7 & Egito & 1.000 & 0.165 & 16 & Indonésia & 1.000 & 1.000 & 25 & Ucrânia & 0.500 & 0.297 \\
\hline 8 & El Salvador & 0.874 & 0.026 & 17 & Mauritânia & 0.500 & 0.012 & 26 & Vietnã & 0.973 & 0.855 \\
\hline 9 & Filipinas & 1.000 & 0.000 & 18 & Moldova & 0.561 & 0.007 & 27 & Zâmbia & 0.571 & 0.053 \\
\hline \multicolumn{10}{|c|}{ Média Global } & 0.748 & 0.167 \\
\hline \multicolumn{12}{|c|}{ Exportação - Renda Baixa } \\
\hline DMU & Economia & $\mathrm{ET}^{*}$ & $E E^{\star \star}$ & DMU & Economia & ET & EE & DMU & Economia & ET & EE \\
\hline 1 & Benin & 0.949 & 0.037 & 9 & Laos & 0.855 & 0.261 & 21 & Tanzânia & 1.000 & 0.001 \\
\hline 2 & Burkina Faso & 0.534 & 0.234 & 10 & Madagascar & 1.000 & 0.193 & 21 & Togo & 1.000 & 0.055 \\
\hline 3 & Burundi & 0.627 & 0.000 & 11 & Maláui & 0.574 & 0.129 & 22 & Zimbábue & 0.714 & 0.000 \\
\hline 4 & Congo, Rep. Dem. & 0.714 & 0.001 & 12 & Mali & 0.841 & 0.088 & & & & \\
\hline 5 & Eritreia & 1.000 & 1.000 & 13 & Moçambique & 1.000 & 0.437 & & & & \\
\hline 6 & Etiópia & 0.686 & 0.316 & 14 & Nepal & 0.493 & 0.085 & & & & \\
\hline 7 & Gâmbia & 1.000 & 0.002 & 15 & Níger & 0.625 & 0.082 & & & & \\
\hline 8 & Guiné & 1.000 & 0.137 & 16 & Quênia & 0.776 & 0.196 & & & & \\
\hline \multicolumn{10}{|c|}{ Média Global } & 0.786 & 0.152 \\
\hline
\end{tabular}

*ET: Eficiência técnica; **EE: Eficiência de escala.

Fonte: elaboração da autora, resultado da análise.

\section{Eficiência nas importações}

De forma semelhante ao que foi exposto no item anterior, são descritos os países eficientes nos quatro grupos de desenvolvimento, pela ótica das importações. A Tabela 6 aponta para as estatísticas descritivas para as medidas de facilitação do comércio relacionadas ao presente fluxo comercial. Mais uma vez, Irlanda e 
França são sublinhadas como as economias menos burocráticas para importar um bem, tendo como exigências apenas dois documentos para os trâmites comerciais. Enquanto República Centro-Africana é o país mais burocrático, exigindo 17 documentos. Os países exigem, em média, mais documentos para importar do que para exportar, dois fatores podem contribuir para essa diferença: as exigências nas importações implicam em maior número de certificações e, além disso, pode haver interesse dos países em proteger seus produtos nacionais.

Assim como para as exportações, os países de renda mais baixa são os que apresentam maior tempo para importar, sendo Quirguistão (renda baixa) e Iraque (renda média alta), os países mais lentos em realizar o despacho aduaneiro. O período médio para liberação das mercadorias é de 75 e 82 dias, respectivamente. Em relação aos custos, Malásia (US\$ 485,00) e Congo (US\$ 7.590,00) são os países menos e mais custosos para importar, nesta ordem.

Tabela 6 - Estatística das variáveis de fronteira por classificação de países, nas importações

\begin{tabular}{l|l|r|r|r}
\hline \multicolumn{5}{c}{ Importação } \\
\hline \multirow{4}{*}{ Renda Alta } & № de documentos & Tempo & \multicolumn{1}{c}{ Custo } \\
& Média & 5.18 & 11.18 & 1117.40 \\
& Máximo & 10.00 & 21.00 & 2484.50 \\
& Desimo & 2.00 & 6.00 & 565.00 \\
& Média & 1.93 & 4.45 & 365.70 \\
\hline \multirow{5}{*}{ Renda Média Alta } & Máximo & 6.45 & 20.45 & 1698.62 \\
& Mínimo & 10.00 & 82.00 & 7590.00 \\
& Desvio Padrão & 3.00 & 8.00 & 485.00 \\
Renda Média Baixa & 2.02 & 16.59 & 1400.64 \\
& Média & 8.18 & 22.00 & 1378.01 \\
& Máximo & 13.00 & 38.00 & 2505.00 \\
& Mínimo & 4.00 & 10.00 & 600.00 \\
& Desvio Padrão & 2.31 & 14.42 & 940.20 \\
\hline \multirow{5}{*}{ Renda Baixa } & Média & 10.00 & 41.00 & 3065.23 \\
& Máximo & 17.00 & 75.00 & 5735.00 \\
& Mínimo & 6.00 & 19.00 & 745.00 \\
& Desvio Padrão & 2.27 & 16.75 & 1613.68 \\
\hline
\end{tabular}

Fonte: elaboração da autora.

Quanto à análise de eficiência, obtêm-se, primeiramente, os escores para países de renda alta (Tabela 7). Os Estados Unidos são o único a operar em escala ótima, sendo também tecnicamente eficiente, junto de Cingapura, França, Hong Kong e Irlanda. 
Tabela 7 - Análise de eficiência nas importações para países de renda alta

\begin{tabular}{|c|c|c|c|c|c|c|c|c|c|c|c|}
\hline \multicolumn{12}{|c|}{ Importação } \\
\hline DMU & Economia & $\mathrm{ET}^{*}$ & $E E^{\star *}$ & DMU & Economia & ET & $\mathrm{EE}$ & DMU & Economia & ET & EE \\
\hline 1 & Alemanha & 0.907 & 0.762 & 17 & Eslovênia & 0.538 & 0.036 & 33 & Luxemburgo & 0.710 & 0.017 \\
\hline 2 & Arábia Saudita & 0.386 & 0.189 & 18 & Espanha & 0.667 & 0.000 & 34 & Malta & 0.455 & 0.010 \\
\hline 3 & Austrália & 0.523 & 0.198 & 19 & $\begin{array}{l}\text { Estados } \\
\text { Unidos }\end{array}$ & 1.000 & 1.000 & 35 & Noruega & 0.599 & 0.073 \\
\hline 4 & Áustria & 0.674 & 0.133 & 20 & Estônia & 0.803 & 0.017 & 36 & Nova Zelândia & 0.544 & 0.050 \\
\hline 5 & Barém & 0.506 & 0.000 & 21 & |Finlândia & 0.729 & 0.090 & 37 & Omã & 0.656 & 0.035 \\
\hline 6 & Bélgica & 0.710 & 0.330 & 22 & França & $\mid 1.000$ & 0.678 & 38 & Países Baixos & 0.749 & 0.208 \\
\hline 7 & Canadá & 0.811 & 0.392 & 23 & Grécia & 0.478 & 0.061 & 39 & Polônia & 0.673 & 0.168 \\
\hline 8 & Catar & 0.428 & 0.036 & 24 & Hong Kong & 1.000 & 0.568 & 40 & Portugal & 0.684 & 0.066 \\
\hline 9 & Chile & 0.576 & 0.072 & 25 & Irlanda & 1.000 & 0.074 & 41 & Reino Unido & 0.814 & 0.437 \\
\hline 10 & Chipre & 0.801 & 0.005 & 26 & Islândia & 0.667 & 0.004 & 42 & Rep. Checa & 0.471 & 0.000 \\
\hline 11 & Cingapura & 1.000 & 0.000 & 27 & Israel & 0.779 & 0.000 & 43 & Rússia & 0.277 & 0.223 \\
\hline 12 & Coreia, Rep. & 0.947 & 0.427 & 28 & Itália & 0.823 & 0.393 & 44 & Suécia & 0.927 & 0.127 \\
\hline 13 & Croácia & 0.417 & 0.000 & 29 & Japão & 0.645 & 0.660 & 45 & Suíça & 0.701 & 0.203 \\
\hline 14 & Dinamarca & 0.963 & 0.074 & 30 & Kuwait & 0.357 & 0.038 & 46 & Uruguai & 0.400 & 0.010 \\
\hline 15 & Emirados Árabes & 0.816 & 0.318 & 31 & Letônia & 0.591 & 0.019 & & & & \\
\hline 16 & Eslováquia & 0.510 & 0.066 & 32 & Lituânia & 0.592 & 0.040 & & & & \\
\hline \multicolumn{10}{|c|}{ Média Global } & 0.681 & 0.181 \\
\hline
\end{tabular}

*ET: Eficiência técnica; **EE: Eficiência de escala.

Fonte: elaboração da autora, resultado da análise.

Novamente, Cingapura foi o maior benchmark, servindo de referência para 36 países de renda alta, seguida de Hong Kong (31), Irlanda (25) e França (5). Tanto nas exportações quanto nas importações, Cingapura, Irlanda e França foram apresentados como países de referência para os ineficientes. Dito isso, pode-se concluir que a eficiência das administrações alfandegárias dessas economias maximiza as entradas e saídas de mercadorias.

Na Tabela 8, é apresentada a eficiência para países de renda média alta. China foi o único país a apresentar economia de escala e, juntamente com Malásia e Panamá, apresentou-se eficiente técnico em importar. O principal benchmark nessa categoria foi Panamá, sendo referência a 27 economias ineficientes, seguido de Malásia (26) e China (8). Os três países apresentam boa qualidade de infraestrutura de transporte, essa variável pode ser fundamental para explicar sua eficiência.

Além disso, no tocante às variáveis de fronteira, Panamá foi o país menos burocrático no grupo dos países de renda média alta, exigindo apenas 3 documentos para importar (Malásia, 4; China, 5 - a média do grupo é 6 documentos). Quanto ao tempo para importar, os dois principais benchmarks são os mais rápidos em despachar mercadorias dentro de sua categoria, Malásia leva 8 dias para liberar uma 
mercadoria importada e Panamá, 9 dias. Na variável custos, as três economias são as menos custosas para realizar importações. A média do grupo para importar um contêiner de 20 pés é de US\$ 1.699,00. Para a Malásia, esse custo é de US\$ 485,00; China, US\$ 800,00; e Panamá, US\$ 965,00. Por essas variáveis, justifica-se porque essas economias servem de modelo para os demais com DMU inferior a 1.

Tabela 8 - Análise de eficiência nas importações para países de renda média alta

\begin{tabular}{|c|c|c|c|c|c|c|c|c|c|c|c|}
\hline \multicolumn{12}{|c|}{ Importação } \\
\hline DMU & Economia & $\mathrm{ET}^{*}$ & $E E^{\star \star}$ & DMU & Economia & ET & EE & DMU & Economia & ET & EE \\
\hline 1 & África do Sul & 0.516 & 0.122 & 13 & Congo, Rep. do & 0.300 & 0.003 & 25 & Montenegro & 0.710 & 0.000 \\
\hline 2 & Angola & 0.341 & 0.026 & 14 & Costa Rica & 0.693 & 0.023 & 26 & Namíbia & 0.457 & 0.000 \\
\hline 3 & Argélia & 0.426 & 0.067 & 15 & Equador & 0.547 & 0.000 & 27 & Panamá & 1.000 & 0.020 \\
\hline 4 & Argentina & 0.396 & 0.073 & 16 & Gabão & 0.400 & 0.001 & 28 & Peru & 0.550 & 0.060 \\
\hline 5 & Azerbaijão & 0.333 & 0.015 & 17 & Hungria & 0.646 & 0.111 & 29 & Rep. Domin. & 0.800 & 0.029 \\
\hline 6 & $\begin{array}{l}\text { Bósnia e } \\
\text { Herzegovina }\end{array}$ & 0.615 & 0.018 & 18 & Iraque & 0.300 & 0.000 & 30 & Romênia & 0.632 & 0.125 \\
\hline 7 & Botsuana & 0.500 & 0.007 & 19 & Jamaica & 0.500 & 0.009 & 31 & Sérvia & 0.545 & 0.033 \\
\hline 8 & Brasil & 0.494 & 0.361 & 20 & Jordânia & 0.545 & 0.037 & 32 & Tailândia & 0.769 & 0.298 \\
\hline 9 & Bulgária & 0.639 & 0.042 & 21 & Líbano & 0.509 & 0.000 & 33 & Tunísia & 0.643 & 0.030 \\
\hline 10 & Cazaquistão & 0.253 & 0.038 & 22 & Macedônia & 0.727 & 0.012 & 34 & Turquia & 0.595 & 0.384 \\
\hline 11 & China & 1.000 & 1.000 & 23 & Malásia & 1.000 & 0.345 & & & & \\
\hline 12 & Colômbia & 0.632 & 0.101 & 24 & México & 0.972 & 0.495 & & & & \\
\hline \multicolumn{10}{|c|}{ Média Global } & 0.588 & 0.114 \\
\hline
\end{tabular}

*ET: Eficiência técnica; **EE: Eficiência de escala.

Fonte: elaboração da autora, resultado da análise.

Na Tabela 9, há os escores de eficiência para a categorias de países de renda média baixa e renda baixa. A Índia é o único país que opera com retornos de escala constante. Na eficiência técnica, o destaque é para Filipinas (19), Geórgia (15), Nicarágua (15), El Salvador (3), Vietnã (1) e Índia (1), o valor entre parênteses indica quantas vezes esses países foram benchmarks em importar, dentro de sua categoria. 
Tabela 9 - Análise de eficiência nas importações para países de renda média baixa e renda baixa

\begin{tabular}{|c|c|c|c|c|c|c|c|c|c|c|c|}
\hline \multicolumn{12}{|c|}{ Importação - Renda Média Baixa } \\
\hline DMU & Economia & $\mathrm{ET}^{*}$ & $\mathrm{EE}^{\star \star}$ & DMU & Economia & ET & EE & DMU & Economia & ET & EE \\
\hline 1 & Afeganistão & 0.400 & 0.000 & 10 & Geórgia & 1.000 & 0.047 & 19 & Nicarágua & 1.000 & 0.025 \\
\hline 2 & Armênia & 0.612 & 0.018 & 11 & Guatemala & 0.841 & 0.079 & 20 & Nigéria & 0.472 & 0.165 \\
\hline 3 & Bolívia & 0.781 & 0.049 & 12 & Guiana & 0.978 & 0.008 & 21 & Paquistão & 0.811 & 0.185 \\
\hline 4 & Camarões & 0.478 & 0.000 & 13 & Honduras & 0.841 & 0.034 & 22 & Paraguai & 0.555 & 0.053 \\
\hline 5 & Camboja & 0.760 & 0.044 & 14 & lémen & 0.658 & 0.044 & 23 & Senegal & 0.745 & 0.032 \\
\hline 6 & Costa do Marfim & 0.441 & 0.065 & 15 & Índia & 1.000 & 1.000 & 24 & Sri Lanka & 0.977 & 0.087 \\
\hline 7 & Egito & 0.916 & 0.314 & 16 & Indonésia & 0.958 & 0.001 & 25 & Ucrânia & 0.532 & 0.000 \\
\hline 8 & El Salvador & 1.000 & 0.050 & 17 & Mauritânia & 0.701 & 0.014 & 26 & Vietnã & 1.000 & 0.784 \\
\hline 9 & Filipinas & 1.000 & 0.327 & 18 & Moldova & 0.534 & 0.020 & 27 & Zâmbia & 0.500 & 0.000 \\
\hline \multicolumn{10}{|c|}{ Média Global } & 0.759 & 0.128 \\
\hline \multicolumn{12}{|c|}{ Importação - Renda Baixa } \\
\hline DMU & Economia & $\mathrm{ET}^{*}$ & $E E^{\star \star}$ & DMU & Economia & ET & EE & DMU & Economia & ET & EE \\
\hline 1 & Benin & 0.846 & 0.363 & 9 & Laos & 0.793 & 0.268 & 17 & Quirguistão & 0.545 & 0.000 \\
\hline 2 & Burkina Faso & 0.562 & 0.266 & 10 & Madagascar & 1.000 & 0.321 & 18 & $\begin{array}{l}\text { República } \\
\text { Centro-Africana }\end{array}$ & 0.353 & 0.000 \\
\hline 3 & Burundi & 0.674 & 0.056 & 11 & Maláui & 0.552 & 0.259 & 19 & Ruanda & 0.667 & 0.000 \\
\hline 4 & Congo, Rep. Dem. & 0.669 & 0.251 & 12 & Mali & 0.570 & 0.137 & 20 & Tanzânia & 1.000 & 0.990 \\
\hline 5 & Eritreia & 0.500 & 0.003 & 13 & Moçambique & 1.000 & 0.702 & 21 & Togo & 0.902 & 0.206 \\
\hline 6 & Etiópia & 1.000 & 1.000 & 14 & Nepal & 0.545 & 0.001 & 22 & Zimbábue & 0.924 & 0.433 \\
\hline 7 & Gâmbia & 1.000 & 0.065 & 15 & Níger & 0.641 & 0.168 & & & & \\
\hline 8 & Guiné & 0.812 & 0.263 & 16 & Quênia & 0.846 & 0.417 & & & & \\
\hline \multicolumn{10}{|c|}{ Média Global } & 0.746 & 0.280 \\
\hline
\end{tabular}

*ET: Eficiência técnica; **EE: Eficiência de escala.

Fonte: elaboração da autora, resultado da análise.

Filipinas é o principal exemplo para os países ineficientes, pois apresenta condições tarifárias favoráveis para que outros países acessem seu mercado interno pelas importações. Além disso, são submetidos a baixas tarifas para acessarem o mercado externo. Quando analisadas em conjunto, as variáveis de fronteira das Filipinas são as melhores entre os países de renda média baixa. O número de documentos (7), o tempo (14) e o custo para importar um contêiner de 20 pés (US\$ $660,00)$ estão bem inferiores à média do grupo $(8 ; 22$; US $\$ 1.378,00$, respectivamente), o que explica o país asiático ser referência para os ineficientes.

Para os países de renda baixa (Tabela 9), Etiópia foi o único que apresentou eficiência de escala, sendo também eficiente técnico e benchmark para 10 economias de renda baixa, seguido de Gâmbia (17), Madagascar (2), Moçambique (3) e Tanzânia (0), que também foram tecnicamente eficientes em importar. $\mathrm{O}$ valor entre parênteses refere-se à quantidade de países ineficientes em que estes foram referência. 


\section{Eficiência geral}

Neste último tópico, realizou-se uma análise de eficiência para todos os 129 países da amostra, a fim de verificar se as economias que foram eficientes e benchmarks em seus respectivos grupos são eficientes numa análise geral. Os escores de eficiência calculados estão dispostos no Apêndice 1. É possível verificar que nas exportações apenas Alemanha e Estados Unidos tiveram eficiência de escala; e, nas importações, Estados Unidos e China. Na eficiência técnica, Alemanha, Cingapura, Estados Unidos, França, Hong Kong e Irlanda foram eficientes tanto em exportar quanto em importar. Dinamarca, Estônia e Malásia foram eficientes técnicos apenas e exportação e China em importação.

Observa-se que todos esses países já foram citados como eficientes quando analisados em seus grupos de referência. Com exceção da China, todas as economias são de renda alta, o que é esperado. As estatísticas descritivas apontam que as economias mais desenvolvidas são aquelas que operam com menores número de documentos, tempo e custo para comercializar. Cingapura foi benchmark para 113 países no quesito exportação e importação, seguida da Irlanda (86 e 87, respectivamente). As mesmas economias também se destacaram como referência para os países de renda alta.

\section{Considerações finais}

O AFC propõe que os membros da OMC adotem medidas para tornarem as transações de mercadorias pelas fronteiras mais harmônicas e simplificadas. Como consequência, haverá uma redução nos custos totais de comércio internacional, o que pode impulsionar o volume exportado e importado.

O objetivo deste trabalho foi analisar a eficiência de 129 países, membros da OMC, em utilizarem as medidas propostas pelo AFC, no ano de 2014, a partir da metodologia DEA. Os principais resultados apontam que os Estados Unidos apresentam eficiência total nas exportações e importações, quando comparados às demais economias da amostra. Alemanha e China também apresentaram eficiência total igual a 1, indicando que operam na escala de produção ótima.

Em relação à eficiência técnica, dez países se destacaram, sendo benchmarks para os países ineficientes, são eles: Alemanha, China, Dinamarca, Estados 
Unidos, Estônia, França, Irlanda, Hong Kong, Malásia e Cingapura, em que o último foi referência para 113 economias. A este resultado é atribuído o fato de que o país asiático possui o sistema de administração de fronteiras muito desenvolvido, suas alfândegas são exemplos para o mundo. Cingapura atende as exigências propostas pelo AFC antes mesmo da sua entrada em vigor.

Ao estender a análise envoltória de dados para países divididos em categorias de desenvolvimento - renda alta, renda média alta, renda média baixa e renda baixa, observou-se que a China se destacou como principal benchmark para os países de renda média alta, para os fluxos de exportações e importações. Na terceira classificação, Indonésia e Filipinas foram as principais referências para os países ineficientes de sua categoria. Para os países de renda baixa, Madagascar e Gâmbia são exemplos para as economias menos desenvolvidas.

Por fim, ressalta-se a importância de os países adotarem as medidas de facilitação de comércio, buscando desburocratizar as transações comerciais com o resto do mundo, reduzir o tempo de contenção das mercadorias nas alfândegas e, finalmente, reduzir os custos associados ao comércio. As exigências que o AFC impõe só trarão benefícios aos países que aderirem a ele. 


\title{
Efficiency analysis from border variables
}

\begin{abstract}
Measures to accelerate and coordinate trade processes are seen progressively as a way of developing and enhancing exchanges between nations. In this sense, the debate on trade facilitation measures gains momentum in multilateral rounds, increasing the influence of border procedures to increase trade. This work aimed to make an analysis of efficiency, using the DEA method, to identify which countries, in 2014, were efficient in increasing their trade flows by using the measures proposed by the Trade Facilitation Agreement. Germany and the United States are, in general, efficient in scale in exporting and importing. However, Singapore has stood out as the main benchmark, its customs administration is one of the best in the world and serves as an example for inefficient countries. China is also a highlight among middle-income countries.
\end{abstract}

Keywords: Trade Facilitation Agreement. Efficiency Analysis. Trade flows.

\section{Análisis de eficiencia para variables fronterizas}

\section{Resumen}

Las medidas que apuntan a acelerar y coordinar los procesos comerciales se ven gradualmente como una forma de desarrollar e incrementar los intercambios entre naciones. En este sentido, el debate sobre medidas de facilitación del comercio gana espacio en rondas multilaterales, al incrementar la influencia de los procedimientos fronterizos para incrementar el comercio. Este trabajo tiene como objetivo realizar un análisis de eficiencia, utilizando el método DEA, para identificar qué países, en 2014, fueron eficientes en incrementar sus flujos comerciales al utilizar las medidas propuestas por el Acuerdo de Facilitación del Comercio. Alemania y Estados Unidos son, en general, eficientes en escala para exportar e importar. Sin embargo, Singapur se destacó como el principal referente, su administración aduanera es una de las mejores del mundo y sirve de ejemplo para países ineficientes. Entre los países en desarrollo, China se destaca en sus procesos comerciales.

Palabras clave: Acuerdo sobre Facilitación del Comercio. Análisis de eficiencia. Flujos comerciales.

Classificação JEL: F13.

\section{Notas}

1 Além desses, Malaui e Nepal (renda baixa) também emitem 11 documentos para exportar.

2 É um sistema tecnológico que integra, em um sistema único, todos os tratamentos administrativos específicos para comercializar o bem, reduzindo consideravelmente o número de documentos e o tempo de retenção das mercadorias nas alfândegas. 


\section{Referências}

BANKER, R. D.; CHARNES, A.; COOPER, W. W. Some models for estimating technical and scale inefficiencies in data envelopment analysis. Management Science, v. 30, n. 9, p. 1078-1092, 1984. CHARNES, A.; COOPER, W. W.; RHODES, E. Measuring the efficiency of decision making units. European Journal of Operational Research, v. 2, n. 6, p. 429-444, 1978.

DJANKOV, S.; FREUND, C.; PHAM, C. S. Trading on time. World Bank Policy Research Working Paper, Washington, 3909, p. 29, 2006.

DOING BUSINESS. Database. Disponível em: http://www.doingbusiness.org/. Acesso em: abr. 2019.

ENGMAN, M. The economic impact of trade facilitation. OECD Trade Policy Working Paper, n. $21,2005$.

HUMMELS, D.; SCHAUR, G. Time as a trade barrier. National Bureau of Economic Research, 2012.

LI, Y.; WILSON, J. S. Trade facilitation and expanding the benefits of trade: evidence from firm level data. ARTNet Working Paper Series, 2009.

LINS, M. P. E.; MEZA, L. A. Análise Envoltória de Dados e perspectivas de integração no ambiente de Apoio à Decisão. Rio de Janeiro: Coppe/UFRJ, 2000.

NAÇÕES UNIDAS. Country Classification. 2014. Disponível em: https://goo.gl/SDWEfj. Acesso em: jul. 2019.

SADIKOV, A. M. Border and behind-the-border trade barriers and country exports. IMF Working Paper, Washington, 07/292, 32 p., 2007.

SOUZA, M. J. P. de; BURNQUIST, H. L. Facilitação de comércio e impactos sobre o comércio bilateral. Revista Estudos Econômicos, v. 41, n. 1, 2011.

WILSON, J. S.; MANN, C. L.; OTSUKI, T. Assessing the benefits of trade facilitation: a global perspective. The World Economy, v. 28, n. 6, p. 841-871, 2005.

WITS. WORLD INTEGRATED TRADE SOLUTION. Database. Disponível em: https://wits.worldbank.org/. Acesso em: abr. 2019.

WEF. World Economic Forum. 2019. Disponível em: https://www.weforum.org/. Acesso em: jun. 2019.

WTO. Speeding up trade: benefits and challenges of implementing the WTO Trade Facilitation Agreement. 2015a. Disponível em: https://goo.gl/Ed6dS7. Acesso em: mar. 2019.

WTO. Trade facilitation in context. 2015b. Disponível em: https://goo.gl/jdfHsx. Acesso em: mar. 2019 . 


\section{Apêndice 1}

Tabela 10 - Análise de eficiência para a amostra de 129 economias

\begin{tabular}{|c|c|c|c|c|c|c|c|c|c|c|c|}
\hline \multirow{2}{*}{$\overline{\mathrm{DMU}}$} & \multirow[b]{2}{*}{ Economia } & \multicolumn{2}{|c|}{ Exportação } & \multicolumn{4}{|c|}{ Importação } & \multicolumn{2}{|c|}{ Exportação } & \multicolumn{2}{|c|}{ Importação } \\
\hline & & $\mathrm{ET}^{*}$ & $\mathrm{EE}^{\star *}$ & ET & $\mathrm{EE}$ & DMU & Economia & & $\mathrm{EE}^{\star \star}$ & ET & EE \\
\hline 1 & Afeganistão & 0.22 & 0.001 & 0.207 & 0 & 66 & Iraque & 0.243 & 0.078 & 0.237 & 0 \\
\hline 2 & África do Sul & 0.492 & 0.084 & 0.411 & 0.084 & 67 & Irlanda & 1 & 0.127 & & 0.074 \\
\hline 3 & Alemanha & & & 0.907 & 0.745 & 68 & Islândia & 0.667 & 0.004 & 0.667 & 0.004 \\
\hline 4 & Angola & 0.283 & 0 & 0.28 & 0.024 & 69 & Israel & 0.749 & & 0.779 & 0 \\
\hline 5 & Arăbia Saudita & 0.487 & 0.393 & 0.386 & 0.176 & 70 & Itália & 0.81 & 0.454 & 0.823 & 0.393 \\
\hline 6 & Argélia & 0.373 & 0.077 & 0.34 & 0.061 & 71 & Jamaica & 0.447 & 0.001 & 0.373 & 0.005 \\
\hline 7 & Argentina & 0.5 & 0.059 & 0.323 & 0.052 & 72 & Japão & 0.946 & 0.604 & 0.645 & 0.627 \\
\hline 8 & Armênia & 0.475 & 0.001 & 0.333 & 0.003 & $7 \overline{3}$ & Jordânia & 0.592 & 0.009 & 0.414 & 0.022 \\
\hline 9 & Austrália & 0.667 & 0.216 & 0.523 & 0.194 & 74 & Kuwait & 0.428 & 0 & 0.357 & 0.034 \\
\hline 10 & Áustria & 0.803 & & 0.674 & 0.133 & 75 & Laos & 0.286 & 0.003 & 0.285 & 0.003 \\
\hline 11 & Azerbaijão & 0.261 & 0.02 & 0.242 & 0.007 & 76 & Letônia & 0.761 & 0 & 0.591 & 0.018 \\
\hline 12 & Barém & 0.567 & 0.028 & 0.506 & 0 & 77 & Líbano & 0.66 & 0.003 & 0.405 & 0 \\
\hline 13 & Bélgica & 0.706 & 0.396 & 0.71 & 0.33 & 78 & Lituânia & 0.721 & 0.036 & 0.592 & 0.038 \\
\hline 14 & Benin & 0.437 & 0.001 & 0.356 & 0.003 & 79 & Luxemburgo & 0.75 & 0.011 & 0.71 & 0.017 \\
\hline 15 & Bolívia & 0.404 & 0.013 & 0.426 & 0.009 & 80 & Macedônia & 0.5 & & 0.373 & 0.007 \\
\hline 16 & Bósnia e Herzegovina & 0.375 & 0.008 & 0.374 & 0.012 & 81 & Madagascar & 0.545 & 0.002 & 0.323 & 0.003 \\
\hline 17 & Botsuana & 0.353 & 0.008 & 0.333 & 0.008 & 82 & Malásia & 1 & 0.314 & 0.992 & 0.211 \\
\hline 18 & Brasil & 0.462 & 0.174 & 0.344 & 0.173 & 83 & Maláui & 0.259 & 0.001 & 0.224 & 0.002 \\
\hline 19 & Bulgária & 0.613 & 0.027 & 0.521 & 0.028 & 84 & Mali & 0.386 & 0.001 & 0.218 & 0.001 \\
\hline 20 & Burkina Faso & 0.271 & 0.003 & 0.195 & 0.003 & 85 & Malta & 0.588 & 0.006 & 0.455 & 0.01 \\
\hline 21 & Burundi & 0.278 & & 0.235 & 0.001 & 86 & Mauritânia & 0.354 & 0.002 & 0.356 & 0.003 \\
\hline 22 & Camarões & 0.331 & 0.007 & 0.238 & 0 & 87 & México & 0.632 & 0.342 & 0.646 & 0.321 \\
\hline 23 & Camboja & 0.566 & 0.009 & 0.475 & 0.01 & 88 & Moçambique & 0.427 & 0.006 & 0.321 & 0.008 \\
\hline 24 & Canadá & 0.857 & 0.371 & 0.811 & 0.392 & 89 & Moldova & 0.326 & 0.002 & 0.265 & 0.005 \\
\hline 25 & Catar & 0.578 & & 0.428 & 0.033 & 90 & Montenegro & 0.494 & 0.001 & 0.566 & \\
\hline 26 & Cazaquistão & 0.215 & 0.079 & 0.19 & 0.037 & 91 & Namíbia & 0.348 & 0.006 & 0.372 & 0 \\
\hline 27 & Chile & 0.571 & 0.083 & 0.576 & 0.068 & 92 & Nepal & 0.256 & 0.001 & 0.251 & \\
\hline 28 & China & 0.547 & 0.003 & & & 93 & Nicarágua & 0.552 & 0.005 & 0.534 & 0.005 \\
\hline 29 & Chipre & 0.857 & 0.001 & 0.801 & 0.005 & 94 & Níger & 0.254 & 0.001 & 0.22 & 0.002 \\
\hline 30 & Cingapura & & 0.538 & & & 95 & Nigéria & 0.326 & 0.122 & 0.231 & 0.049 \\
\hline 31 & Colốmbia & 0.545 & 0.054 & 0.45 & 0.048 & 96 & Noruega & 0.75 & 0.118 & 0.599 & 0.072 \\
\hline 32 & Congo, hepútica & 0.318 & 0 & 0.232 & 0.003 & 97 & Nova Zelândia & 0.698 & 0.04 & 0.543 & 0.048 \\
\hline 33 & Congo, República do & 0.223 & 0 & 0.2 & 0.003 & 98 & Oma & 0.617 & 0.067 & 0.656 & 0.033 \\
\hline 34 & Coreia & 0.924 & 0.001 & 0.947 & 0.411 & 99 & Países Baixos & 0.857 & 0.28 & 0.749 & 0.205 \\
\hline 35 & Costa do Marfim & 0.318 & 0.012 & 0.222 & 0.016 & 100 & Panamá & 0.939 & 0.001 & 0.825 & 0.011 \\
\hline 36 & Costa Rica & 0.566 & 0.012 & 0.555 & 0.014 & 101 & Paquistão & 0.588 & 0.033 & 0.447 & 0.051 \\
\hline 37 & Croácia & 0.463 & & 0.417 & & 102 & Paraguai & 0.379 & 0.009 & 0.295 & 0.01 \\
\hline 38 & Dinamarca & & & 0.963 & 0.073 & 103 & Peru & 0.583 & 0.045 & 0.444 & 0.046 \\
\hline 39 & Egito & 0.727 & 0.036 & 0.575 & 0.075 & 104 & Polônia & 0.563 & 0.219 & 0.673 & 0.168 \\
\hline 40 & El Salvador & 0.462 & 0.007 & 0.435 & 0.012 & 105 & Portugal & 0.715 & 0.069 & 0.684 & 0.064 \\
\hline 41 & Emirados Árabes & 0.929 & 0.254 & 0.814 & 0.302 & 106 & Quênia & 0.326 & 0.002 & 0.293 & 0.004 \\
\hline 42 & Equador & 0.398 & 0.025 & 0.443 & 0 & 107 & Quirguistão & 0.24 & 0.001 & 0.196 & 0 \\
\hline 43 & Eritreia & 0.289 & 0.029 & 0.244 & 0 & 108 & Reino Unido & 0.75 & 0.454 & 0.814 & 0.437 \\
\hline 44 & Eslováquia & 0.512 & 0.081 & 0.51 & 0.066 & 109 & República C & 0.222 & 0 & 0.143 & 0 \\
\hline 45 & Eslovênia & 0.616 & 0.04 & 0.537 & 0.033 & 110 & República C & 0.638 & 0.163 & 0.471 & 0 \\
\hline 46 & Espanha & 0.667 & 0.277 & $\mid 0.667$ & 0 & 111 & República Dominicana & 0.75 & 0.009 & 0.479 & 0.017 \\
\hline 47 & Estados Unidos & & & & & 112 & Romênia & 0.522 & 0.065 & 0.451 & 0.061 \\
\hline 48 & Estônia & & 0.016 & 0.803 & 0.017 & 113 & Ruanda & 0.314 & & 0.262 & 0 \\
\hline 49 & Etiópia & 0.329 & 0.004 & 0.242 & 0.017 & 114 & Rússia & 0.307 & 0.458 & 0.277 & 0.22 \\
\hline 50 & Filipinas & 0.769 & & 0.687 & 0.07 & 115 & Senegal & 0.5 & 0. & 0.431 & 0.005 \\
\hline 51 & Finlândia & 0.75 & 0.097 & 0.728 & 0.085 & 11 & Sér & 0.5 & 0.014 & 0.386 & 0.016 \\
\hline 52 & França & & 0.608 & & 0.678 & 117 & Sri Lanka & 0.756 & 0. & 0.612 & 0.02 \\
\hline 53 & Gabẩo & 0.41 & & 0.326 & & 118 & Suécia & 0.906 & 0.158 & 0.927 & 0.125 \\
\hline 54 & Gâmbia & 0.489 & 0 & 0.591 & & 11 & & 0.857 & 0.259 & 0.701 & 0.203 \\
\hline 55 & Geórgia & 0.706 & & 0.647 & 0.007 & 120 & Tailẩndia & 0.76 & 0 & 0.638 & 0.225 \\
\hline 56 & Grécia & 0.667 & 0.034 & 0.478 & 0.057 & 121 & Tanzânia & 0.427 & 0 & 0.274 & 0.014 \\
\hline 57 & Guatemala & 0.364 & 0.013 & 0.445 & 0.014 & 122 & Tog & 0.491 & 0.001 & 0.417 & 0.002 \\
\hline 58 & Guiana, RC & 0.62 & 0.002 & 0.612 & 0.002 & 123 & Tunísia & 0.716 & 0.018 & 0.517 & 0.026 \\
\hline 59 & Guiné & 0.497 & 0.002 & 0.358 & 0.002 & 124 & Turquia & 0.465 & & 0.396 & 0.251 \\
\hline 60 & Honduras & 0.545 & 0.004 & 0.445 & 0.006 & 125 & Ucrẩnia & 0.34 & 0.052 & 0.288 & 0 \\
\hline 61 & Hong Kong & & 0.016 & & 0.549 & 126 & Uruguai & 0.481 & 0.01 & 0.4 & 0.009 \\
\hline 62 & Hungria & 0.519 & 0.148 & 0.545 & 0.104 & 127 & Vietnã & 0.742 & 0.2 & 0.782 & 0.139 \\
\hline 63 & lémen & 0.493 & 0.002 & 0.326 & 0.012 & 128 & Zâmbia & 0.286 & 0.01 & 0.25 & \\
\hline 6 & Índia & 0.411 & 0.351 & 0.364 & 0.424 & 129 & Zimbábue & 0.295 & 0 & 0.25 & 0.007 \\
\hline & Indonésia & 0 771 & & 0.68 & & & & & & & \\
\hline & & & 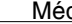 & ia Glob & & & & 661 & 92 & 0.499 & 0.093 \\
\hline
\end{tabular}

*ET: Eficiência técnica; **EE: Eficiência de escala.

Fonte: elaboração da autora, resultado da análise. 